\title{
Building Strategy Quality
}

\author{
Widodo \\ Departement of Mangement, Islamic Sultan Agung University \\ PO.box 1054/SM, Semarang, Indonesia \\ Tel: 62-813-2578-4761 E-mail: widodos3@ yahoo.com
}

Received: February 9, 2011 Accepted: March 18, 2011 doi:10.5539/ijbm.v6n8p180

\begin{abstract}
The main aim this paper is (1) To construct a theoretical model for strategy quality and their effects on organizational performance of all BPRs in Central Java Province (2) To describe the phenomenon of strategy quality and their effects on organizational performance of all BPRs in Central Java Province (3) To empirically test the effects of cross-functional integration, communication quality, comprehensiveness, commitment, capabilities, strategy content and adaptability on organizational performance (4) To empirically test effects of commitment, smart working, communication quality, collaborating behavior and learning orientation on organizational performance. (5) To empirically test the effects of procedural knowledge, experience, process control, output control on organizational performance

This research finding showed that managerial implication of the effort in improving organization working quality through strategy quality development as follow: (1) the aspect of strategy planning, organization working quality can be reached through the improvement of strategy content quality which is built with adaptation ability. 2).The aspect of strategy implementation quality, organization working quality can be reached through smart working pattern improvement which is built with coordination. 3). The aspect of strategy evaluation quality, organization working quality can be reached through the improvement of output control which is built by controlling process. 4). Previous studies controversy (research gap) can be ended by contribution of intervening variable in the empirical model, that is strategy content and adaptability on strategy planning quality. Then smart working pattern and coordination on strategy implementation quality and process controlling and output controlling on strategy evaluation quality. The recommendation is necessary to improve the implementation in each research variable
\end{abstract}

Keywords: Strategy of planning quality, Strategy of implementation quality, Strategy of evaluating quality, Organizational performance

\section{Introduction}

A basic problem in strategic management is how a corporate organization can achieve its superior performance and maintain its competitive advantage (Teece, D.J, Pisano. G, and Shuen. A, 1977). Strategy is a success key influencing organizational performance (Bokor. D.W, 1995; Ferdinand (2002). This is due to the the fat that a strategy is a comprehensive planning which explains the position of a company's competitiveness. Not all businessmen, however, succeed with the strategy they own. This condition correlates to their strategy quality. A qualified strategy is a strategy built by qualified strategy formulation, implementation and evaluation (Menon, 1999). A good strategy development process should be based on assumpsion that it has to have proper strategy content, with a qualified formulation process as well as clarity and firmness in its implementation (Vadarajan. J, 1999).

A strategy process focusing on strategy planning means how the strategy is arrived at (Ferdinand, 2002). Most of strategy planning models accommodates incomprehensively variance and complexity of a phenomenon (Hart Banbury, 1994). Empirically, a wide scope process using various performance measurements, results in insignificant knowledge accumulation (Wooldrrige and Floyd, 1996). According to Covin J.G. Dess (1977) there is a limitation on decision process format of organizational strategic in general which takes other organizational format.

Previous studies have showed that variables of strategy planning quality involving comprehensiveness of study (Menon et al, 1999), communication quality (Johlke M.C, 2000; Gobel, DJ, 2004), commitment (Deery, S.J, 2005), cross-functional integration quality (Song I.M, 2000) have influences on performance. However, other studies show that comprehensiveness of study (Gima, K.A \& Murray, J.Y, 2004), communication quality (Menon et al, 1999), commitment (Menon et al, 1999), cross-functional integration quality (Menon et al, 1999) have no influences on performance.

A study by Hax and Majluft (2001) shows the majority of company unable to implement its formulated strategy. Some recent empirical research findings demonstrate only 20-30 percentage of organizational strategic planning can be executed, the rest is spontaneous activities based on intuition, instinct and certain managerial consideration. 
These condition demands the way this strategy can be articulated in implementation, in order to be implemented and give opportunity to improve organizational performance (Ferdinand, 2002). However, previous study indicates that variables of strategy implementation quality, including: commitment (Deery, S.J and Iverson, R.D, 2005), communication quality (Johlke, M.C, 2000; Gobel, D.J, 2004), have influence on organizational performance. While other studies include commitment (Noble c.H and Mokwa, M.P, 1999) and communication quality (Menon, et. Al, 1999).

Furthermore, strategy implemented by organization should be constantly evaluated, whether it is still fit with both internal and external organizational environment. FW Gueck (1996) argues that evaluation process is closely related to ongoing efforts of activity controlling. Organizational performance will depend on how evaluation process and strategy control have been carried out (Ferdinand, 2002). Based on behavior-based control (Oliver and Anderson, 1994), strategy controlling has an impact on organizational performance. Piercy. Nigel F, however, showed that strategy controlling has no influence on organizational performance. Other study on variables of strategy evaluation quality, experience, has an influence on performance (walker, 1997). While Manfred Krafft (1999) finds that experience has influence on performance. Based on the, a question is raised: "how to develop a qualified strategy in order to stimulate the improvement of organizational performance?"

\section{Proposition Development Grand Theoretikal Model Strategy Quality}

\subsection{Proposition of Organizational Learning}

Organizational learning is a process in which an organization learns to get skills in creating, learning and transferring knowledge and also adapts organization's attitude to reflect company's learning output (Garvin, 1993). While Goldman Lynda explains that organizational learning is a system consisting of steps of actions, doers and processes which enables an organization to alter information into valuable knowledge, which in turn improves long term adaptive ability.

Learning process enables people to act through many ways which fit surrounding environment. According to Ferdinand (2002) organization doing process learning as part of organizational learning as an integrated system will result in ambiguity including: first, organization is a bridge which is ready to react and adapt to change. Second, organization learns how to utilize organizational learning experience to create a creative strategy. Third, a quality of process will be reflected from the existence of many kinds of commitments, including commitment to make consensus. Good organizational learning will enable the development of many assets and capabilities that furthermore increase the formulated strategy quality which in turn has opportunity to improve performance.

Learning organization is viewed as an interactive process in which manager makes changes using some steps designed to analyze organization and environment. These steps are manager learning in the process of strategic changes (Rajagopalan. N, 1997).

Contingency theory explains that organizational learning is a result of adaptation of internal variable to environmental variables. The differences in the intensity of external environment diversity need the intensity of decision making difference. This is to adapt organizational resources to existing external environment (Sharma dan Arogan-Corera (2003). Zajac study (2000) shows that strategy changes in saving and borrowing industry in US can be predicted based on intensity differences on resources owned by difference companies. It is also showed thathigher fit in intensity between strategy and external business environment can create higher competitiveness.

Manager perception about business environment influences the implemented strategy. In this case, managers can interpret environmental issue as a threat or opportunity in the same time. In order to maintain alignment between changing managerial perceptions and the ability to handle environment, an organization must develop dynamic ability in the form of an environment-proactive strategy (Sharma dan Arogan-Corera, 2003).

A successful organization is an organization with strong culture that is aligned with the organization's environment (Hofstede, 1997). Strong culture is characterized by organization core value in general. The more members, who receive core values, agree on interest level and feel bonded with their organization, the stronger organizational culture will become (Robbin, S, 1997). That is why adaptability is an important variable which needs to be considered in explaining the importance of organizational culture toward organizational success. Study of Hessket \& Kotter (1992) in 200 companies in some Asian, European, and American countries found that strong and adaptive culture has significant advantage and contribution toward organizational performance improvement in long term. So, it needs to be differentiated between enduring identity and having continuity identity. Enduring identity means an organizational identity tend to be permanent although environment changes. Having continuity identity means organizational culture identity needs to be interpreted and given different meaning in line with the demand on environment changing (contextual), while organization values and core believes are maintained or interpretation of organizational culture need to be dynamic (Hact, 1993).

Based on a learning lens perspective, strategy change process is viewed as a creative process, managers make changes with a series of steps designed to analyze organizational culture and environment. These steps are called organizational learning (Rajagopalan, N, 1997). Based on above explanation, the first proposition is as follow:

Proposition 1: Organizational learning is a dynamic and interactive process in developing capabilities. 
Environmental changing will lead a company to organizational learning. Organizational learning needs support and must be developed as organizational culture.

\subsection{Proposition Strategic asset}

Strategy management approaches are classified into what approach and how approach (Hendrawan et al, 2003). According to Miller (1998) strategy management approach consists of content and process. One of the questions in content approach is what makes the company successful? Or explaining "this is what we have to do". While for process approach, one of the questions is how the strategy is built or explain "this is the way we do"

Strategy is integration between resources and internal expert of organization and external environment's opportunity and threat. Resources and Capability of company is a basis to formulae strategy, because resources and internal organizational capabilities provide basic guidance for organizational strategy (Grant 1991). Furthermore it explains that basic requirement to achieve market strength is an obligation of the existence of "barrier to entry". Knowing organizational competence is a prerequisite before the company could make strategic decision, including one regard to market entry and exit (Hit, Ireland dan Hoskisson, 2001). A question is raised about what should be fulfilled when resources and capability are considered as real strategic factor to get competitive advantage level ( $\mathrm{F}$ 2003).

Resources and capability is base to formulate strategy. This is based on two reasons: (1) resources and internal capability of organization provide basic guidance for company strategy. (2) resources and capability is source of primary profit for company (Grant. Robert. M, 1991). Capability is frequently developed in certain functional fields, such as brand management or is developed through the combination of physical resources, human resources, and technological resources in the corporate level. So, capability can be high quality excellence, product innovation, manufacture process flexibility, and such (Amit \& Schomaker, 1991).

Furthermore, manager challenges will be understanding, developing, protecting and mobilizing resources and capability through a way which will maintain competitive advantage of organization that finally will provide good profit from spent capital. According to Williamson (1975) certain resources can experience market failure, or experience inability to be traded in the market. There are some factors which cause market failures, such as too small quantity, opportunity and condition of information which easily impacted by bad condition. That is why resources and capability should be a collection of strategic asset which become basis of competitive advantage (Bogaert et al, 1994).

According to Amit \& Shoemaker (1993) strategic asset is rare resources and capabilities, uneasily traded; difficult to be imitated by competitors, durable, can be used to convert value to profit. These strategic assets can be categorized into a bigger bundle such as financial asset, physical asset, human resource asset, technological asset, and intangible asset (Grant, 1991). Challenges facing manager are related to strategic asset needed to yield company profit. Basic sources which have competitive advantage is strategic asset concept (Amit \& Schoemaker 1991). It should be decided then an effort to develop recent and future strategic assets. Not all company resources and capabilities are strategic assets; it means that assets with competitive values have potency to become competitive advantage. some of this resource and capability might not competent, because they fail to outperform other competitors.

Prahalad (1998) and Ferdinand (2002) studies explain that competence (strategic asset) can be maintained through learning process, this process will result in excellent resource and capability beyond the competitors, so that core competences as strategic assets is difficult to be imitated by competitors. Lado. et al (1992) explains four types of organizational competence as potential resources to get sustained competitive advantage as follow: 1). Management competence. According to Wesley and Minzberg (1989), managerial competence is competence of manager in providing and implanting a vision and empower organization member to realize that vision. Besides, managerial competence is also managerial skills to create relationship with its environment. 2). Input-based competence. Input-based competence is simultaneously influenced as well as influences managerial vision (Prahala \& Hamel 1990), forms scope and direction of knowledge exploitation and provides capability to organization to create and share values to customers. 3). Transformational competences. Transformational competence describes all organizational capabilities needed to change input into profitable output. Organizational capabilities include culture and learning; 4). Output competence. Output-asset competence includes all knowledge- based intangible strategic assets such as company image, product and service quality as well as customer loyalty. This competence needs financial resource, technology and human resources in big amount, which are developed in adequate time and yield future economical profit flows (Barney, 1991).

Learning process makes human resources to act in many ways in accordance with its circumstance. The action reaction of employees enables them to learn. Organizational learning will make the company to identify potential resources and competences. Long life learning develops a natural process to accumulate knowledge and competence which in turn gives direct impact toward developed strategy performance (Ferdinand, 2002). Based on the above description, the second proposed proposition is as follow:

Proposition 2: Strategic assets are resources and capabilities which have excellence as prerequisite to improve strategy quality. 


\subsection{Proposition Strategy Quality}

Menon, B and H study (1996); F (2004) explains that performance improvement is determined by business strategy which is used. Strategy is overall planning which explain competitiveness position of a company (Mintzberg dan Quin 1991). Strategy is a bundle of methods used for improving, producing and selling actual products and services $(\mathrm{P}, 1996)$. Organizational strategy is decision pattern related to some important things, which are used for: (1) guidance, which is used by organization in facing its environment. (2) Influencing internal organization both structure as well as process and (3) improving organizational performance (Hambrick, 1990). A qualified quality strategy is a strategy which is built by qualified strategy planning, implementation and evaluation (Menon, Bharadwaj dan Howell, 1996).

\subsubsection{Strategy Planning}

Literature study about strategy planning is diverse, this happens because the situation changes over time (Reid 1989). Strategy planning process consists of understanding of various problems, existing trends and phenomenon, regarding to knowledge development process in the form of a vision and strategy to achieve relevant vision. The resulted targets and objectives become a guidance to achieve relevant strategy and to bring into reality the stated vision (Hax dan Majluf 1996).

Strategy planning stresses on ability of organization to adapt to its environment while trying to achieve and or to change various business goals (Hax dan Majluf 1996). This can be achieved through learning process, which in turn will stimulate necessary action to be conducted to ensure mutual benefit side (DeGuess 1988). According to Sloteragaaf. R.J (2004) one of the central elements of strategic planning process is competence or strategic asset. While based on resource-based view theory, basic manifest of heterogeneous resources will encourage a company to competitive advantage condition and form basic ability of company organization (Barney 1991; Wernefel 1984).

Menon et al strategy planning model (1999) explains that strategy planning is an interactive process built in organizational background which gives uniqueness to a strategy. Strategy development pattern is reflected from the freedom of organizational movement to experiment with extensive innovation culture. No matter what the type of the organization is, some standard processes have been developed as prerequisite of strategy development, it should be set out from relevant and comprehensive situational analyses, considering some resources and capabilities of the organizations, through a cross-functional integration and cross-functional process which could produce a good process synergy, supported by willingness to have commit in a good and positive ways. This process will result in a creative strategy which has potential for improving performance. Planning process will produce content planning (Sloteragaaf. R.J, 2004). Content strategy is related to the types of strategy decision (Bokor Donal.W dan Olson Philip D 1995). Or content strategy answers what become strategy or an effort to study extensively type of strategy which will be implemented (Feerdinand 2002).

Slotegraaf, R.J and Dickson, P.R study (2004) describes that planning capability is related to content of the planning itself. Furthermore, the dimension of content planning is as follow: (1) comprehensiveness, which reflects program and situational factors. More specifically, comprehensiveness shows intensity of organization efforts to make decisions and activate resources of chosen strategy (Ferdinand, 1984). This includes organization capability to create some alternatives which produce competitive advantage, ability to consider the possibility that certain alternative can be realized as well as ability to discard other alternatives considered to have no benefit (M 1999). According to Day and Nedundi (1994), written planning is a model of collective mental applied by company to design and handle some internal and external environment. So, a comprehensive approach for content planning will result in more extensive scope. A company which has strong ability in doing planning has high possibility in taking not only situational topic, but also various type of program into planning content. (2) Plan Budgets, is important for planning, in which used budgeting technique will directly influence the amount of budget which will be allocated to various planned programs (P, 1987). Planning budget based on rules, such as activity and marginal profit analysis result, will provide a more effective resource allocation, since one of key factors of planning capability is competence in allocating resources (CK 1988). So, planning capability will identify utility of action in allocating resources to support planned strategy. According to Slotergraaf, R.J and Dickson, P.R, that principal goal of planning is to give information to management about product and market situation, fund and budget. So, a company which has good capability in doing planning will also use rational budgeting approach in planning.

\subsubsection{Strategy Implementation}

Strategy implementation is an application which takes resources into consideration. Strategy implementation is an action process of a planning (Kotler 1997). According to Varadarajan, Jayachandran (1999) strategy implementation answers how strategy will be put into operation. The success of organization strategy depends on the success of its strategy implementation (Bonoma 1984). According to Noble, C.H (1999), the success of strategy implementation depends on factors, such as manager autonomy level, functional contribution level, and facility as well as reward.

Strategy implementation based on commitment theory explains that; people differ in their organizational 
commitment intensity. Commitment intensity is also related to various characteristics the company has and various characteristics owned by relevant person. Characteristics related to commitment are sense of trust toward senior manager, satisfaction to participation intensity in decision making process, higher intensity of organization decentralization and positive attitude toward organization (Buchanan, 1975). One of important factors of commitment is political access defined as the ability to identify particular problems and to maintain relevant problems. Ability to in decision making process will not produce commitment, because what could result on commitment is the possibility to find an adequate forum to significant problems for the relevant person. Furthermore, it can be concluded that Commitment theory explains manager commitment intensity toward strategy implementation process. If there is suitability of low intensity goal, so manager commitment toward strategy implementation is also low (Mohrman, 1979).

Mokwa, MP study explains that strategy implementation is started from: First, role factor consist of involvement intensity and manager's autonomy level. Second factor is realization strategy including adequate scope, management support, and vision clarity. An increase in commitment dimension will increase the success of strategy realization. A well processed strategy needs professional competence (Ferdinand, 2002). Furthermore, a qualified strategy is a strategy which can be articulated in implementation. This condition demands structure need and organizational skills to implement. Study Barney (1991) explains that strategy articulation should be supported by capability and competence. There are three resources which produce organizational commitment including: 1) physical capital, 2). Human capital, and 3). Organizational capital.k

Determining organizational structure is principal factor in organizing existing activities and human resource of an organization in order to get all jobs successfully done. Literature study shows that structure follows chosen strategy (Willson. H, 2001). This is caused by changes in environments tends to lead to strategy changing, which finally lead to changing in organization structure. So, strategy, structure and environment are interrelated. The speed of structure adaptation to appropriate strategy enables a company to get a competitive advantage (Kazanjian. R.K, 1996). Barney study describes that one of the "invisible capitals" which need to be developed is organizational capability portfolio, such as control system and coordination. Informal organizational relationship, job position level system, which in general attach to company history has high value which is difficult to be imitated.

\subsubsection{Strategy Evaluation}

Contingency theory (Keeley. M, 1996) explains the relationship between strategy evaluation and evaluation as follow: 1). Behavior-based Evaluation procedure, a procedure which emphasis on the specified prediction expectation of performance which makes it very systematic in its structure and suit primary to definite jobs. 2). Goal-based evaluation procedure, which emphasis on unspecified prediction expectation of performance which makes its structure rather organic and suit primary to jobs with moderate level of uncertainty. 3). Assessment-based evaluation procedure, a procedure which emphasis on unspecified prediction expectation which makes its structure highly organic and suit primary to jobs high level of uncertainty.

Above guidance shows that if the level of job uncertainty increases, the task of assessment will move from what is being evaluated to who is doing evaluation. Ferdinand study (2002) explains that antecedents of a qualified strategy evaluation are evaluation process and evaluation instrument. Strategy evaluation process is designed to ensure that a gap between expected and wanted goals will be covered by chosen strategy. According to FW Glueck (1996) evaluation process is closely related to current activity control effort. So, according to Rowe and Carlson (1994) the following aspects must be achieved: 1). Management control, based on past performance and historical data. 2). Real-time control, which focus on aspects of control technique to gain suitable information. 3). Realization management, which focus on conformity between organizational goals and effectiveness. 4). Adaptive control, which relate to determining the fastest and most effective way to respond to changes. 5). Strategic control which involves how to anticipate or develop in order to minimize the possibility of distortion from expected results.

The scope of controlling includes outcome control, activity control, and ability control (Anderson 1998). Outcome control based on output concept or outcome control (A, 1987). Through outcome control, supervisor more focus on outcome target achieved by employees, increase on the effort and control will provide feedback. This kind of control provides little information for employees regarding the reason why they are demanded to achieve outcome. When the supervisor conducts outcome control orientation, they ask employees to try to achieve strategy and higher result. Then orientation of activity control will focus more on routine activity with existing mechanism, such as reporting periodical visit report, conducting weekly visits, maintaining relationship or interaction with clients as well as organizing existing budget. This activity control orientation looks at and monitor how employee do their daily routine jobs (Merchan, 1985). Supervisors through activity control orientation specifically monitor employee activities day to day and give feedbacks for activities done by employees such as: visit level, number of visited correspondence, etc. Empirical findings show that low attention level on activity control is due to limited time and space (Denisi, 1999). And control orientation to ability focuses on skill development and support employee's quality behavior such as skills of negotiation, communication, understanding as well as ability to make presentation. Based on the review of the prior research, this study attemps to test the following proposision 
Proposition 3: Strategy quality is the level of comprehensiveness and alignment of strategy planning with process and clarity of strategy implementation process and strategy evaluation. Organizational qualified strategy will improve organizational performance.

Based on literature review explained above, a grand theoretical model in this study is presented in the supplementary appendix (Figure 1):

\section{Methodology and Findings}

\subsection{Sample}

The object of this study is 120 rural banking in central java province. The number of rural banking is distributed to 75 rural banking in Bank of Indonesian's coordination region Semarang office, 29 rural banking in Bank of Indonesian's coordination region of Surakarta office, and 16 rural banking in Bank of Indonesian's coordination region of Purwokerto office.

\subsection{Structural Equation Model}

After analyzing model through confirmatory factor, then each indicator in this fit model is used to define latent construct, so that full model of structural equation model (SEM) AMOS can be analyzed. The analysis result can be referred in the appendix. It is showed from full model of structural equation model (SEM) (attached) that this model fit to data used in this research. It is showed by chi-square, probability, CMIN/DF, TLI which was within the range of expected value although GFI and AGFI are accepted marginally.

\subsection{Hypothesis Testing}

Estimation parameter of causality correlation among hypothesized constructs are analyzed using critical ratio criteria which is identical to t-test regression analysis is presented in the attachment. Estimation parameter of causality correlation among hypothesized constructs is analyzed using critical ratio criteria which is identical to $\mathrm{t}$-test in regression analysis showing that the hypothesis is accepted.

\section{Discussion}

\subsection{Empirical Model Strategy of Quality Planning}

The hypothesis 1 was supported showing that strategy content quality has influence on organization performance, so that the level of organization performance will be highly influenced by strategy content quality. Strategy content quality is what becomes strategy (how organizations actually behave)or an effort to study extensively the articulation of the chosen strategy. So, strategy content serves as guidance for managers in putting plan into action when the organization suffers changes. Strategy content which is rationally chosen will be potential in reducing change intensity. Then, strategy content can also integrate resources with some steps of special action, so that resource allocation will be able to increase relevant action success. This research finding is consistent with the findings of previous study (Slotegraaf, R.J and Dickson, P.R study, 2004). This is why strategy content quality has to implement in order to improve organization performance.

The result supports the hypothesis 2 , which stated that-functional integration has influence on strategy content. Cross-functional integration is an important element of organization sustainability to win competition by optimizing existing functions properly. This step can also be organization ability to capture environment feedbacks, to respond as well as to provide good service in the future. Cross-functional openness and communication are highly needed in order to respond to environment. Problems emerges from a function can be helped in analysis and solution by other functions professionally and conceptually. Unsolved problem in one of the functions can be discussed and solved through coordination among existing organizational functions. This steps need to be taken in organizational culture so that employees are not introvert (proactive) and afraid to take initiative and afraid to take risk (Hand et al 1998). As a result, organizational openness and communication will have influence on responding to environment. An effective cross functional coordination is expected to be able to trigger active participation by each function in order to achieve general organizational goals. It needs effective support and excellent leadership in coordinating cross-functions, support and participation among functional fields, and interdependence inter function. This finding supports a study by Weiss L and Hoffer J (2004). Thus, cross-function integration is required to improve strategy content quality.

The acceptance of hypothesis 3 shows that communication skills have influence on strategy content quality. Communication quality is a degree of how communicated content is accepted and understood by other parties within a relationship. A quality of communication can be defined as the development of formal and informal communication during a period of strategy making. Interaction frequency will influence trust on a relationship. Quality and frequency of communication is factor determining convincingly mutual understanding among members in a relationship to achieve common goals. This finding supports a study by Weiss L and Hoffer, J (2004). So, communication quality is required in order to improve strategy content quality.

The acceptance of hypothesis 4 shows that comprehensive study has influence on strategy content quality. Comprehensive study is an activity in designing members thoroughly and widely for searching market information, designing various alternatives action, testing various explanation and usage of specific criteria in development decision and strategy implementation. Comprehensiveness of study in strategy development can trigger an effort 
to get various option and solution. This condition improves the ability to analyze information, stimulate effort, checking alternatives deeply, and create willingness to find a new and better ways in conducting various tasks. This research finding support Ferdinand's study (2002). thus, comprehensive study needs to be conducted in order to improve strategy content quality.

The acceptance hypothesis 5 shows that adaptability has influence on organizational performance. Adaptability is ability to adapt to chance in organization environment. Adaptability of an organization has to develop norms and believes which support ability in accepting and interpreting various signalsfrom environment and convert into cognitive changes and behavior. The success of an organization depends on internal adaptation to environment. A company which has a competitive advantage among competitors, demands the manager to think critically, in a way toadapt to environment. This research finding supports study conducted by Gibbons, PT (2003); Deborah S.Noble (2000). Therefore, adaptability is required to improve organization performance.

The acceptance of hypothesis 6 shows that adaptability has influence on strategy content quality. Adaptability is ability to adapt to chance in organization environment. Adaptability of an organization has to develop norms and believes which support ability in accepting and interpreting various signals comes from environment and converts into cognitive changes and behavior. The success of an organization depends on internal adaptation to environment. This research finding support study of Pit and Kanne Mayer (2000). So, adaptability is required to improve strategy content quality.

The acceptance of hypothesis 7 shows that commitment to consensus has influence on adaptability. Commitment to consensus is employee's relative strength in identify their participation in organization. This is characterized by: 1). Acceptance of organizational values and objectives. 2). Readiness and willingness to try seriously on the organization's behalf. 3) Willingness to maintain a membership in an organization (taking part in organization). Employees with a strong organizational commitment are more likely to have higher participation in organization. Their absenteeism is related to six leave .so that intentional absence is lower than employees with lower tie. Higher commitment employees have strong willingness to stay working with their employees in order to give contribution for their common objectives. Because of Increase in identification and trust to organization, so highly committed individual will get involve in their jobs totally, as it is a way to contribute to achieve organization objectives. Highly committed employees will contribute any effort for organization interest. This research finding supports the study by Moday, et.al. (1998); (Gibbon. PT (2002).So, commitment to consensus is required to improve adaptability.

The acceptance of hypothesis 8 shows that capability has influence on adaptability. Capability is a process based on information. It can be tangible, unique as long term development process through interaction process from various resources. Human resources capability showed by the instruments of level of skill and expertise. This research finding supports the study of Queen (1999). So, capability needs to be improved in order to improve adaptability.

\subsection{Empirical Model strategy quality of implementation}

The acceptance of hypothesis 9 shows that the higher commitment to consensus the employee has the higher smart working pattern. Smart working pattern is adaptive behavior (adaptation behavior). Behavior related to knowledge development is also considered as an aspect of smart working pattern. So, smart working as a behavior is leaded to develop knowledge about knowledge usage in working condition is an ability to adapt to organizational environment. This research finding shows that commitment has influence on smart working pattern. Commitment to consensus is relative strength of the employees in identifying their involvement in organization. This is characterized by: 1). Acceptance of organizational values and objectives. 2). Readiness and willingness to try seriously in the name of organization. 3) Willingness to maintain a membership in an organization (become part of organization). This research finding supports the study of Leong et al (1994). So, commitment needs to be improved in order to improve smart working.

The acceptance of hypothesis 10 shows that the higher smart working pattern, the higher organizational performance. Organizational performance is measured by: 1). Profitability level of organization compared with the industrial average level. 2) Market share level compared with average level of industry.3). Organization Efficiency compared with average level of industry. 4) market position compared with average level of industry. This research finding shows that smart working pattern has influence on organizational performance. While, smart working pattern is an adaptive behavior. A behavior related to knowledge development is also considered as an aspect of smart working pattern. So, smart working as a behavior is leaded to develop knowledge about knowledge usage in working condition is an ability to adapt to organizational environment. This research finding supports study of Sujan, Weitz and Umar (1994); Ferdinand (2004). So, smart working needs to be conducted in order to improve organizational performance.

The acceptance of hypothesis 11 shows that the higher learning orientation, the higher smart working pattern of human resource. Smart working pattern is an adaptive behavior related to knowledge development is also considered as an aspect of smart working pattern. So, smart working as a behavior is leaded to develop knowledge about knowledge usage in working condition is an ability to adapt to organizational environment. This research 
finding shows that learning orientation has influence on smart working pattern. While learning orientation is about how people respond and interpret performance situations, with some indicators as follows: 1). Knowing new things. 2). The existence of training. 3) The existence of customer feedbacks. 4). continually develop. This research finding supports the study of Sujan and Kumar (1994). So, learning orientation needs to be developed in order to improve smart working pattern.

The acceptance of hypothesis 12 shows that the higher communication quality, the better coordination. Coordination describes an effort of organization in adapting and influencing organizational activity or objective integration process and activities of separated units. Without coordination, employees as well as departments will lose a view of their roles in organization. This research findings shows that communication quality has influence on coordination. While communication quality is a degree of how communicated content accepted and understood by other parties in a relationship. Communication quality can be defined as formal and informal communication development during strategy making. This research supports the study of Anderson and Weitz (1989); Moher et al (1999). Therefore, communication quality is required in order to improve strategy content quality.

The acceptance of hypothesis 13 shows that the higher behavior collaboration, the better coordination. Coordination describes an effort of organization in adapting and influencing organizational activity or objective integration process and activities of separated units. Without coordination, employees as well as departments will lose a view of their roles in organization. This research findings shows that behavior collaboration has influence on coordination. While, behavior collaboration is an understanding to understand the needs of other function, consequently it can improve communication. It will facilitate cross functional interaction or ease communication. This research finding support a study by Dyier, Song and Jihong (2000); Tjosvold (1991). Thus, collaboration is required to improve coordination.

The acceptance of hypothesis 14 shows that the better coordination, the better smart working. Smart working pattern is adaptive behavior Behavior relating to knowledge is considered an aspect of smart working pattern. Accordingly, smart working as behavior directed toward developing knowledge about utilizing this knowledge in working condition is an ability to adapt to the changes in the environment. This research finding shows that coordination has influence on smart working pattern. Coordination describes an effort of organization in adapting and influencing organizational activity or objective integration process and activities of separated units. Without coordination, employees as well as departments will not engage to their role in organization. This research finding supports study of Sujan, Weitz and Umar (1994); Mohr et al (1999). subsequently, coordination needs to be developed in order to improve smart working pattern.

The acceptance of hypothesis 15 shows that the better coordination, the higher organization performance. Smart working pattern is adaptive behavior. Organizational performance is measured by: 1). Profitability level of organization compared with the industrial average level. 2) Market share level compared with average level of industry.3). Organization Efficiency compared with average level of industry. 4) Market position compared with average level of industry. This research finding shows that coordination has influence on organizational performance. Coordination is an ability to manage factors influencing relationship among human resources. Coordination leads to improved jobs in work unit. Then, the job improvement is the same as exploiting unique opportunity and lead to mutual synergy for joint business. Although, this research finding supports previous research conducted by Porter (1991); Johson (1999), but the result of descriptive analysis of performance variable is moderate (is not optimal yet). So, job coordination needs to be well conducted to improve organizational performance.

\subsection{Empirical Model Strategy quality of Evaluation}

The acceptance of hypothesis 16 shows that the better process control, the higher organizational performance will be. Organizational performance is measured by: 1). Profitability level of organization compared with the industrial average level. 2) Market share level compared with average level of industry.3). Organization Efficiency compared with average level of industry. 4) Market position compared with average level of industry. This research finding shows that process control has influence on organizational performance. Process control look at and monitor how employees do their daily routine work. Supervisors specifically monitor employee activities day to day and give feedbacks for activities done by employees such as: visit level, number of visited correspondence, etc. This research finding supports empirically study of Kohli, AJ (1988); Morris, Michael, H (1991). So, process control needs to be well conducted to improve organization performance.

The acceptance of hypothesis 17 shows that the better output control, the higher organization performance. Organizational performance is measured by: 1). Profitability level of organization compared with the industrial average level. 2) Market share level compared with average level of industry.3). Organization Efficiency compared with average level of industry. 4) Market position compared with average level of industry. This research finding shows that output control has influence on organizational performance. While output control is control which more focus on outcome target achieved by employees, increase on the effort and control will provide feedback. This kind of control provides little information for employees regarding the reason why they are demanded to achieve final output. When the supervisor conducts output control orientation, they ask employees to 
try to achieve strategy and higher result. This research finding support a study by Weiz and Sujan (1986). So, the work of output control needs to be well conducted to improve organization performance.

The acceptance of hypothesis 18 shows that the better process control, the better output control. Output control is control which more focus on outcome target achieved by employees, increase on the effort and control will provide feedback. This kind of control provides little information for employees regarding the reason why they are demanded to achieve final output. When the supervisor conducts output control orientation, they ask employees to try to achieve strategy and higher result. This research finding shows that process control has influence on output control. While, process control look at and monitor how employees do their daily routine work. Supervisors specifically monitor employee activities day to day and give feedbacks for activities done by employees such as: visit level, number of visited correspondence, etc. This research finding supports the study by Grinfinth (2002). So, the work of process control needs to be well conducted to improve output control.

The acceptance of hypothesis 19 shows that the higher procedure knowledge, the better process control. Process control look at and monitor how employees do their daily routine work. Supervisors specifically monitor employee activities day to day and give feedbacks for activities done by employees such as: visit level, number of visited correspondence, etc. This research finding shows that procedure knowledge has influence on control process. While procedure knowledge is related to the intensity of manager ability in specify activities need to be conducted by employees in order to achieve knowledge target. These kinds of knowledge has obvious characteristic in routine job situation. This research finding support empirically study of MacInnis (1989). So, the work of procedure knowledge needs to be well conducted to improve process control.

The acceptance of hypothesis 20 which shows that the higher procedure knowledge, the better output control. Output control is control which more focus on outcome target achieved by employees, increase on the effort and control will provide feedback. This kind of control provides little information for employees regarding the reason why they are demanded to achieve final output. When the supervisor conducts output control orientation, they ask employees to try to achieve strategy and higher result. This research finding shows that procedure knowledge has influence on output control. While procedure knowledge is related to the intensity of manager's ability in specifying activities the employees need to do in order to achieve target. Such knowledge has an obvious characteristic in routine job situation. This empiric finding supports the study of MacInnis (1989). So, the work of procedure knowledge needs to be well conducted to improve output control.

The acceptance of hypothesis 21 which shows that the higher degree of intensive experience, the better process control. Process control and monitor how employees do their daily routine work. Supervisors specifically monitor employee's daily activities and give feedbacks for activities done by employees such as: visit level, number of visited correspondence, etc. his research finding shows that intensive experience has influence on process control. While intensive experience is an experience which has working variance in organization. This research finding supports the study of William B.Locander (2007). So, the work of intensive experience is required to improve process control.

The acceptance of hypothesis 22 which shows that the higher degree of intensive experience, the better output control. Output control is control which focuses more on outcome target achieved by employees, increase on the effort and control will provide feedback. This kind of control provides little information for employees regarding the reason why they are demanded to achieve final output. When the supervisor conducts output control orientation, they ask employees to try to achieve strategy and higher result. This research finding shows that intensive experience has influence on output control. While intensive experience is an experience which has working variance in organization. This research finding support the study of William Stuart A Trossini (2002). So, intensive experience is required well to improve output control.

\section{Managerial Implication}

\subsection{Strategy Quality of planning}

a).Adaptability policy refers to continuously monitor the changing in environment by finding out relevant information. (b) Content strategy policy is matching the available resources and the chosen strategy content. It is not recommended to imitate the content strategy of other rural banking due to the difference in strength and weakness as well as opportunity and threat .c).Comprehensiveness of study policy is improving the development of alternative actions, utilizes opportunity through intensive analysis. d).Cross functional integration policy improve: 1). Level of cross functional involvement in regard to the degree of coordination. 2).cross functional communication quality in regard to punctuality and information validity in each department. 3). Harmony of cross functional relations in regard to the degree of coordination on communication aspects, interaction and cooperation among departments which is responsible for satisfaction in interaction. e).Capability policy is improving the development and training systematically and continuously. It is aimed at developing knowledge. f).Commitment policy, increasing sense of belonging of organization by distributing their involvement in various important events of the organization. g).Communication quality policy doing informal activity and higher level of managerial decreasing the level of communication dominance. 


\subsection{Strategy Quality of Implementation}

a). Coordination policy is coordinating based on the form and communicating tasks to do, and level of dependency of various sub units doing the task. b). Smart working pattern policy, increasing self confidence to own ability to change behavior and adapt our behavior based on existing situation. c). Learning orientation policy is conducting structured, continuous, and competent training and developments .d). Behavior collaboration policy is improving openness, mutual trust communication).Commitment policy, improving sense of belonging of organization by distributing involvement in various organization activities. f). Communication policy, conducting informal activity and higher managerial level, decreasing communication dominance.

\subsection{Strategy Quality of Evaluation}

a).Process control policy more focuses more on outcome achieved by employees. b). Output control policy emphasize on how manager influence the employee to do their tasks, by process control it is expected that employee behavior fits with expected behavior in order to produce the outcome which in accordance with existing mechanism's). Intensive experience policy is determining career path based on experience variance. d). Procedure knowledge policy is improving manager's ability is specifying activity which has to be done by employees in order to achieve goals.

\section{References}

Amit, R., and Schomaker. PJ.K. (1993). Strategic Asset and Organizational Rent. Strategic Management Journal, 33-46.

Anderson Paul F. (1999). Marketing Strategic Planning and the Theory of the Firm. Journal of Marketing, 4615 21.

Ashwin W. Joshi. (2009). Continuous Supplier Performance Improvement: Effects of Collaborative Communication and Control. Journal of Marketing, Vol. 73. 133-150.

Baker. Willam.E. dan Sinkula., \& James M. (1999). The Synergistic effect of Market Orientation and Learning Orientation on Organizational Performance. Journal of the Academy of Marketing Science, 27. (4), 411-427.

Barney, Jay. (1991). Firm Resources and Sustained Competitive Advantage. Journal of Management, 17, 99-120.

Bourgeis L.J., and Brodwin David. (1994). Strategic Implementation: Five Approaches to an Elusive Phenomenon. Strategic Management Journal, 5 (3), 24 -32.

Brian Smith. (2003). The effectiveness of marketing strategy making processes: A critical literat. Journal of Targeting, Measurement and Analysis for Marketing, 11 (3). 273 - 281.

Cravens David W. (1998). Implementation Strategies in the market-driven Strategy Era. Journal of the Academy of marketing Science, 237-241.

Cuming. J., and Theng B, S. (2006). The Keys to Succesfull Knowledge Sharing. Journal of Management General, Vol 131.No.4.Sumer.

David Hunger \& Thomas L. Wheelen. (1996). Strategic Management. Addison-Wesley.

Dess. G.D., Lumpin., G.T., \& Covin. J.G. (1997). Entrepreneurial Strategy Making and Firm Performace: Test Contigency and Configurational Models. Strategic Management Journal, 677 -689.

Dwiyer, Schurr, OH. (1987). Developing Buyer-Seller Relationship. Journal of Marketing, 51 (April).

Ferdinand, Augusty. (2002). Marketing Strategy Making: Proses dan Agenda Penelitian. Jurnal Sain Pemasaran Indonesia, Vol I, No. 1. pp.1- 22.

Fiske. Hartley. Nigel S. Holls. (1998). Measuring and Using Brand Equity. Journal of Advertising Research, November / December. 9-21.

Gima.K.A \& Murray .J.Y. (2004). Antecendents and Outcomes of Marketing Strategy Comprehensiness. Journal of Marketing, Vol.63.pp.33-46.

Glueck F.W and Jauch. L.R. (1989). Strategic Management and Business Policy. Mc Graw-Hill Book. Co

Grant.Robert M. (1991). The Resource-based Theory of Competitive Advantage: Implications for Strategy Formulation. California Management Review, 33 (3).p.114.

Gupta Anil K and Govindrajan. (1986). Business Unit Strategy, managerial Characteristics, and Business Unit Effectiveness at Strategy Implementation. Academy of Management Journal, 27 (1).p25.

Guth. William D and Macmillan Ian.C. (1996). Strategy Implementation Versus Middle management Self-Interest. Strategic management Journal, 7,313-323.

Han J. K. Kim N. Srivaastava. R. K. (1998). Market Orientation and Organizational Performance: Is Innovation a Missing Link? Jounal of Marketing, 62, 45-53.

Hendrawan.S.Et.al. (2003). Advanced Strategik Management. PT. Gramedia Pustaka Utama: Jakarta

Hrebianak, Lawrence G. (1999). Implementing Strategy. Chief Executive, 57, 74-82 
Hunger D.J., and Wheelen T.L. (1996). Strategic Management. Addison-Weley. Ublising Company, Inc. Ian H. Wilson. (1990). Enviroment Scanning and Strategic Planning. Conference Papers.

Jaeger A.M dan Baliga. B. R. (1985). Control Systems and Strategic Adapon: Lessons from the Japanese Wxperience. Strategic Management Journal. 6, 115-134.

Janis Forman. (2005). How Corporate Communication Influences Strategy Implementation, Reputation and the Corporate Brand: An Exploratory Qualitative Study. Corporate Reputation Review, Vol. 8, No. 3, pp. 245-264

Javad Kargar and Robert A. Blumental. (1999). Succesfull Implementation of Strategic decision in Small Community Banks. Journal of Small Business Management, 10 -19.

Jaworski. B. J et al. (1993). Control Combinations in Marketing: Conseptual framework and Empirical Evidence. Journal of Marketing, 57-69.

Junfeng Z.C dan Benedetto D.T. (2009). Product Development Strategy Product Innovation Performance, and the Mediating Role of Knowledge Utilization: Evidence from Subsidiaries in China Journal of International Marketing, American Marketing Association, Vol. 17, No. 2, pp. 42-58.

Khing William R. (1993). Evaluating Strategic Planning System. Strategic Management Journal, 263-277.

Kohli, A.Kand Jaworski. (1990). Market Orientation: The Construct, Research Propotion and Managerial Implication. Journal of Marketing, 54 (April), 1-18.

Krafft, Manfred. (1999). An Empirical Investigation of The Antecendens of Sales Force Control Systems. Journal of Marketing, 6, 120-134.

Lado, A A., Boyd, N.G \& Wright, P. (1992). A Competence-Based Model of Sustainable Competitive Advantage: Toward a Conceptual Integration. Journal Management, 18, 77-91.

Menon A, Bharadwaj S.G, Adidam P, J, \& Edison S.W. (1999). Antecendents and Consequence of Marketing Strategy Making: Model and Tes. Journal of Marketing, Vol 63.p.18-40.

Menon A, Bharadwaj S.G, and Roy Howell. (1996). The Quality and Effectiveness of Marketing Strategy: Effect of functional and disfunctional conflict in intraorganiztional relationship. Journal of Marketing, Vol 24. No.4 p.299-313.

Mildred Golden Pryor, Donna Anderson, Leslie A. Toombs and John H. Humphreys. (2007). Strategic Implementation as a Core Competency. Journal of Management Research, Vol. 7, Number 1.pp:1-16.

Mintzberg. H. (1990). The Design scholl; reconsidering the basic premise of strategic management. Strategic Management Journal, 11: 171-195.

Mokwa .Michael.P dan Noble Charles H. (1999). Implementing Marketing Strategies: Developing and Testing a Managerial Theory. Journal of Marketing, 57-73.

Moshe Farjaoun and Linda Lai. (1997). Similarity Judgments in Strategy Formulation: Role, process and Implication. Strategic Management Journal, Vol 18, 255-273.

Norus.J. (2006). Building Sustainable Competitive Advantage from Knowledge in the region: The Industrial Enzymes Industry. European Planning Studies, Vol. 14, No. 5, June 2006

Oliver .Richard L dan Anderson. E. (1987). Perspectives on Behavior -Based Versus Outcome-based Saleforce Control Systems. Journal of Marketing, 76-88.

Papadakis V. M., Liokas S., and Chanbers D. (1998). Strategic Decesion Making Procesess: The Role of Management and Context. Strategic Management Journal, 115 -127.

Pareek, Dhruv Grewal and Stephen W. Brown. (1994). Consumer Satisfaction and Perceived Quality: Complementary of Devergant Construct? Journal of Applied Psycology, Vo. 79 No.6, .875-885.

Perce \& Robinson. (2003). Strategic Management: formulation, Implementation and Control. Eight Edition Mc Grw-Hill

Piercy.F.Nigel, Baldaup A and Craves David W. (2001). Examing Business Strategy, Sales management and Salesperson Antecendents of Sales Organization effectiveness. The Journal of Personal Sailing \& Sales Management, 21, 109 -121.

Quinn. JJ., and Hart. S. (1993). Roles executives play: CEOs, behavior complexity, and firm performance. Human Relation, 46, 543-574.

Rajagopalan. N. dan Spretzer. G. M. (1997). Toward A theory of Strategic Change: A Multi- Lens perspective and Integrative Framework. Academy of Management Review, 48-79.

Reed, R and De Fillipi, R. (1990). Causal Ambiguity Barrier Iminitation and Sustainable Competitive Advantage. Academy Management Review, 88-102.

Sharma. Sanjay. (2003). A. Contigency Resouce-based View of Proactive Corporate Enviromental Strategy. Academy of Management Review, 28 (1) p.77. 
Sinkula. J. M, Baker. M.R dan Noordewier. T. (1997). A Framework for market-based Organizational learning : Linking Values, Knowledge, and Behavior. Journal of the Academy of Marketing Science, 25 (4), 305-318.

Song X. M, Hie. J dan Dyer.B. (2000). Antecendents and Cnsequence of Marketing Manager' Conflict-Handling Behaviors. Journal Marketing, Vol.64 (January), 50-66.

Stuart Hart. (1994). How Strategy Making Proceses Can Make Diference. Strategic Management Journal, 251 -265 .

Teece, G. Pisano and A. Shuen. (1997). Dinamic Capabilities and strategic Management. Strategic Management Journal, Vol18: 7 p. 509-533.

Varadarajan. P. Rajan dan Jayachandran. S. (1999). Marketing Strategy: An Assesment of the State of the Field and Outlook. Journal of the Academy of Marketing Science, 120-143.

Science, 88-100.

(1999). Strategy Content and Process Perspectives Revisited. Journal of the Academy of marketing

Vincent Gruis, Nico Nieboer and Andrew Thomas. (2004). Strategic Asset Management in the Social Rented Sector: Approaches of Dutch and English Housing Associations. Urban Studies, Vol. 41, No. 7, 1229-1248.

Yang. J. (2008). Antecedents and Consequences of Knowledge Management Strategy: the case of Chinese high technology firms. Production Planning \& Control, Vol. 19, No. 1, January, 67-77.

Table 1. Standardized Regression Weight Empirical Model Planning Strategy

\begin{tabular}{|l|c|l|c|c|c|l|l|}
\hline \multicolumn{2}{|l}{} & Stand.Estim & S.E. & \multicolumn{1}{c|}{ C.R. } & \multicolumn{2}{|c|}{ Goodness-of-fit-Index } \\
\hline ADAPTABILITY & $<--$ & COMMITMENT & 0.253 & 0.121 & 2.422 & X-Chi-square & 403.159 \\
\hline ADAPTABILITY & $<--$ & CAPABILITY & 0.244 & 0.132 & 2.210 & Probobability & 0.067 \\
\hline STRATEGY_CONTENT & $<--$ & INTEGRATION & 0.232 & 0.106 & 2.359 & RMSEA & 0.031 \\
\hline STRATEGY_CONTENT & $<--$ & COMUNICATION & 0.206 & 0.099 & 2.167 & GFI & 0.82 .6 \\
\hline STRATEGY_CONTENT & $<--$ & COMPREHENSIVENESS & 0.238 & 0.093 & 2.422 & AGFI & 0.791 \\
\hline STRATEGY_CONTENT & $<--$ & ADAPTABILITY & 0.242 & 0.101 & 2.608 & CMIN/DF & 1.114 \\
\hline PERFORMANCE & $<--$ & ADAPTABILITY & 0.248 & 0.108 & 2.411 & TLI & 0.975 \\
\hline PERFORMANCE & $<--$ & STRATEGY CONTENT & 0.213 & 0.096 & 2.130 & CFI & 0.978 \\
\hline
\end{tabular}

Table 2. Standardized Regression Weight Empirical Model Implementation Strategy

\begin{tabular}{|l|c|l|c|c|l|l|l|}
\hline \multicolumn{2}{|l|}{} & Stand.Estim & S.E. & \multicolumn{1}{|c|}{ C.R. } & \multicolumn{2}{|c|}{ Goodness-of-fit-Index } \\
\hline COORDINATION & $<--$ & COMUNICATION & 0.248 & 0.105 & 2.474 & X-Chi-square & 310.095 \\
\hline COORDINATION & $<--$ & BEHAVIOR_COLLABORATION & 0.255 & 0.098 & 2.482 & Probobability & 0.157 \\
\hline SMART_WORKING & $<--$ & LEARNING_ORIENTATION & 0.308 & 0.104 & 3.213 & RMSEA & 0.027 \\
\hline SMART_WORKING & $<--$ & COORDINATION & 0.298 & 0.097 & 3.129 & GFI & 0.839 \\
\hline SMART_WORKING & $<--$ & COMMITMENT & 0.218 & 0.128 & 2.320 & AGFI & 0.803 \\
\hline PERFORMANCE & $<--$ & COORDINATION & 0.242 & 0.108 & 2.389 & CMIN/DF & 1.084 \\
\hline PERFORMANCE & $<--$ & SMART_WORKING & 0.299 & 0.106 & 2.970 & TLI & 0.985 \\
\hline & & & & & CFI & 0.987 \\
\hline
\end{tabular}


Table 3. Standardized Regression Weight Empirical Model Evaluation Strategy

\begin{tabular}{|l|l|l|r|r|r|r|r|}
\hline \multicolumn{2}{|l|}{} & $\begin{array}{r}\text { Stand } \\
\text { Estimate }\end{array}$ & S.E. & C.R. & \multicolumn{2}{|c|}{ Goodness-of-fit-Index } \\
\hline PROCESS_CONTROL & $<-$ & EXPERIENCE & 0.236 & 0.097 & 2.269 & X-Chi-square & 98.215 \\
\hline PROCESS_CONTROL & $<--$ & PROCEDURE_KNOWLEDGE & 0.171 & 0.121 & 2.687 & Probobability & 0.193 \\
\hline OUTPUT_CONTROL & $<--$ & EXPERIENCE & 0.250 & 0.094 & 2.583 & RMSEA & 0.033 \\
\hline OUTPUT_CONTROL & $<--$ & PROCEDURE_KNOWLEDGE & 0.289 & 0.118 & 3.058 & GFI & 0.907 \\
\hline OUTPUT_CONTROL & $<--$ & PROCESS_CONTROL & 0.274 & 0.102 & 2.807 & AGFI & 0.870 \\
\hline PERFORMANCE & $<--$ & OUTPUT_CONTROL & 0.306 & 0.113 & 2.948 & CMIN/DF & 1.129 \\
\hline PERFORMANCE & $<--$ & PROCESS_CONTROL & 0.275 & 0.118 & 2.647 & TLI & 0.986 \\
\hline & & & & & CFI & 0.989 \\
\hline
\end{tabular}

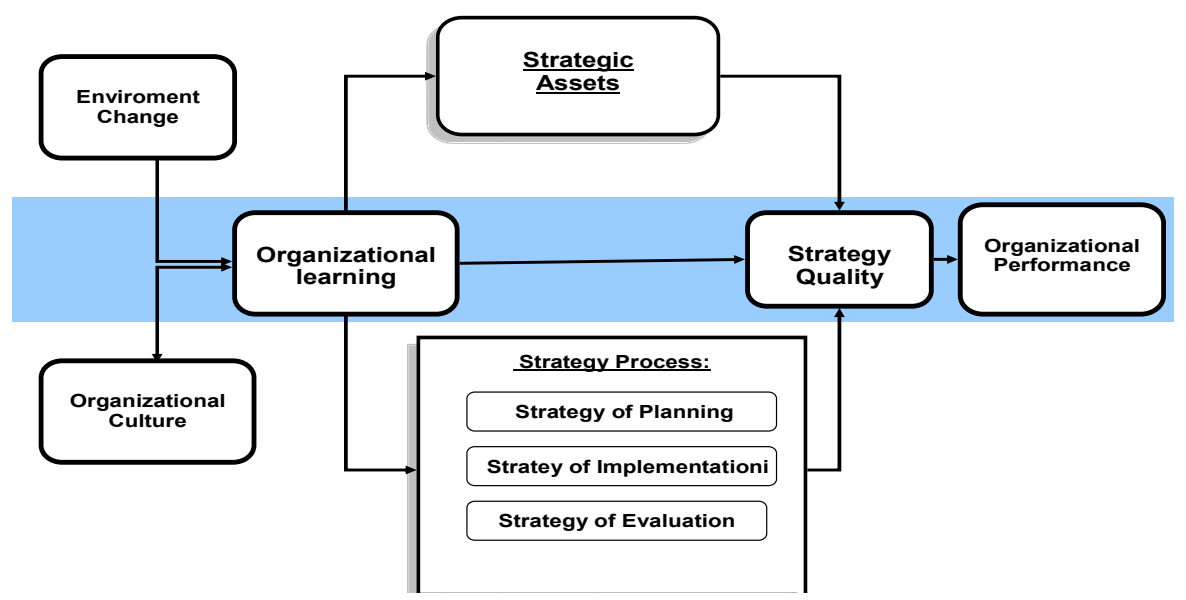

Figure 1. Grand Theory Model Strategy of Quality 